\title{
The Influence of Chitosan on the Oral Bioavailability of Acyclovir-a Comparative Bioavailability Study in Humans
}

\author{
Marlies Kubbinga • Mai Anh Nguyen • Petra Staubach • Steven Teerenstra • Peter Langguth
}

Received: 13 June 2014 / Accepted: 26 December 2014 / Published online: 22 January 2015

(C) The Author(s) 2015. This article is published with open access at SpringerLink.com

\begin{abstract}
Purpose The effects of chitosan hydrochloride on the oral absorption of acyclovir in humans were studied to confirm the absorption enhancing effects reported for in vitro and rat studies, respectively. Methods A controlled, open-label, randomized, 3-phase study was conducted in 12 healthy human volunteers. Zovirax $200 \mathrm{mg}$ dispersible tablets co-administered with doses of 400 and $1000 \mathrm{mg}$ chitosan $\mathrm{HCl}$ were compared with Zovirax only.

Results The expected increased absorption of acyclovir was not observed. On the contrary, mean area under the plasma concentration-time curve (AUCO- $12 \mathrm{~h}$ ) and maximal plasma concentration $\left(\mathrm{C}_{\max }\right)$ decreased following concomitant chitosan intake ( 1402 versus 1017 and $982.0 \mathrm{ng} \cdot \mathrm{h} / \mathrm{ml}$ and 373 versus 208 and $235 \mathrm{ng} / \mathrm{ml}$, respectively). In addition, $T_{\max }$ increased significantly in presence of $1000 \mathrm{mg}$ of chitosan from I to $2 \mathrm{~h}$.

Conclusions The results of this study in human volunteers did not confirm an absorption enhancing effect of chitosan. Reference values were comparable to literature data, whereas addition of chitosan resulted in significant opposite effects on $C_{\max }, T_{\max }$ and
\end{abstract}

Electronic supplementary material The online version of this article (doi: | 0. I007/s | | 095-0 | 4- | 6 | 3-y) contains supplementary material, which is available to authorized users.

\section{Kubbinga}

Centre for Health Protection, National Institute for Public Health and the

Environment, Bilthoven, The Netherlands

M. Kubbinga $\cdot$ M. A. Nguyen $\cdot$ P. Langguth $(\triangle)$

Institute of Pharmacy and Biochemistry, Johannes Gutenberg University

Mainz, Staudingerweg 5, 55I28 Mainz, Germany

e-mail: langguth@uni-mainz.de

M. Kubbinga $\cdot \mathrm{S}$. Teerenstra

Medicines Evaluation Board, Utrecht, The Netherlands

P. Staubach

Department of Dermatology, Clinical Research Center, University

Medical Center, Mainz, Germany
AUC. Additional studies are needed to investigate the cause of the discrepancy. The observed variability and complex potential interactions may complicate the use of chitosan $\mathrm{HCl}$ in oral pharmaceutical formulations.

KEY WORDS bioavailability - biopharmaceutics classification system · biowaiver · excipient interactions · pharmacokinetics

\section{ABBREVIATIONS}

(HP)LC (High pressure) liquid chromatography

AUC Area under the curve

AUC Area under the curve

BCS Biopharmaceutics classification system

$\mathrm{Cl} \quad$ Confidence interval

Cmax Maximum plasma concentration

CV Coefficient of variation

DD Degree of deacetylation

EMA European Medicines Agency

GMR Geometric mean ratio

$\mathrm{HCl} \quad$ Hydrochloride

kDa kiloDalton

MS Mass spectrometry

MW Molecular weight

P-gp P-glycoprotein

Ph.Eur. European Pharmacopoeia

Tmax Time point at which the maximum concentration is measured

\section{INTRODUCTION}

Permeation enhancement has been a research topic in pharmaceutics for decades. Increasing the absorption of drugs 
with low permeability may for instance aid the reduction of the variability in bioavailability as well as reduce the administered dose of an active substance. Examples of absorption modulators are acetylcystein, supposedly acting via reduction of the mucous layer by disrupting disulfide bridges; surfactants, polymers and chelating agents potentially interfering with the tight junctions, and substances interfering with absorption or efflux transporters (1-3).

Chitosan and its derivatives have been described as potential permeability enhancers acting via a disruptive effect on the tight junctions between the epithelial cells (4-9). Chitosan is a heteropolysaccharide derived from natural source; characterized by variable molecular weights, degrees of deacetylation (DD) and salt forms (10).

Acyclovir is a BCS class III substance that is predominantly absorbed via the paracellullar route and has a low and variable bioavailability of $10-30 \%(11,12)$. Some studies suggest the existence of a saturable carrier system or a limited absorption window. Most of the drug is renally excreted in untransformed state $(13,14)$. Chitosan was shown to increase the in vitro permeability of acyclovir across Caco-2 monolayers and the absorption of acyclovir in the rat (15-17). In the absence of clinical studies in humans, the translation of these effects in cell culture and animal models to humans currently remains unclear. The aim of the study presented here was to test the effects of chitosan hydrochloride on the oral absorption of acyclovir in human volunteers.

\section{MATERIALS AND METHODS}

\section{Materials}

Zovirax 200 mg dispersible tablets (GlaxoSmithKline, Austrian license number 1-18043) were used as reference product. Chitosan hydrochloride (chitosan $\mathrm{HCl}$ ) of pharmacopoeial quality was obtained from Heppe Medical, Halle; degree of deacetylation (DD) $93.05 \%$, viscosity $1 \%$ in water at $20^{\circ} \mathrm{C} 5.9 \mathrm{mPas}$, molecular weight (MW) 30-400 kDa. It was dispensed into quantities of 400 and $1000 \mathrm{mg}$ and labeled by Löwen Apotheke in Hochspeyer, Germany. The powders released by the Department of Pharmaceutical Technology and Biopharmaceutics of the Johannes Gutenberg University in Mainz, Germany. Acyclovir reference material was purchased from Fagron. All other materials were purchased from Sigma Aldrich.

\section{Study Design}

A controlled, open-label, randomized, 3-phase study was conducted at the Clinical Research Center of the University Hospital in Mainz, Germany. The clinical trial protocol (EudraCTNr. 2010-023882-22) was approved by both the relevant Ethics Committee (Landesärztekammer Rheinland-Pfalz) and the
German competent authorities (Bundesinstitut für Arzneimittel und Medizinprodukte, BfArM) and the study was performed in accordance with the Declaration of Helsinki. Adult, male and female healthy volunteers were included after a health check based on interview, blood pressure, blood parameters and ECG. Taking into account the variation coefficients as presented previously by Vergin et al. in a bioequivalence study with $200 \mathrm{mg}$ acyclovir products and considering an estimated minimum effect size of $30 \%$ as potentially clinically relevant, a number of 12 volunteers was selected for this exploratory study (18). Participants did not take part in another clinical study in parallel and did not take part in one within the preceding 90 days. Other exclusion criteria were: alcohol abuse or medication dependency in anamnesis, known hypersensitivity to study medication, active liver disease or unexplained increased levels of serum transaminases, intake of prescription drugs in the last 1-2 months, a recent (90 days) history of cytomegalovirus or systemic herpes infection(s) or recurrent systemic infections of herpes viruses, pregnancy and lactation, renal dysfunction. The subjects received Zovirax on the first trial day and were then randomly assigned to either the sequence $1000 \mathrm{mg}$ followed by $400 \mathrm{mg}$ chitosan $\mathrm{HCl}$ or vice versa. This resulted in a 2-treatment (400 vs 1000 mg chitosan HCl), 2-sequence crossover design with pretreatment by Zovirax. This study design allowed evaluation of the pharmacokinetics of acyclovir, without potential interference of chitosan. A wash-out phase of 7 days was applied for each treatment.

Zovirax tablets were used as reference and the same tablets, co-administered with a known quantity of chitosan $\mathrm{HCl}$, were used as test 'formulations'. All products were dispersed in $100 \mathrm{~mL}$ water and administered with another $150 \mathrm{~mL}$, resulting in a total volume of $250 \mathrm{~mL}$ water. Start concentrations of $1.6 \mathrm{~g} / \mathrm{L}(0.16 \%)$ and $4.0 \mathrm{~g} / \mathrm{L}(0.4 \%)$ chitosan $\mathrm{HCl}$ were thus obtained, in line with those described in literature $(0.1 \%$ $0.5 \%)(15,16)$. The maximum chitosan dose was limited to $1 \mathrm{~g}$ in view of the practical feasibility of oral intake of the quantity as a single dose and the related limited relevance of higher quantities as a potential excipient in an actual solid oral dosage form.

Subjects entered the studies fasting for at least $9.5 \mathrm{~h}$. The first meal was offered $4 \mathrm{~h}$ post-dose. The medication was administered with a total of $250 \mathrm{~mL}$ water; subjects had access to more water from $1 \mathrm{~h}$ post-dose on and consumed at least $1.4 \mathrm{~L}$ mineral water during the $12 \mathrm{~h}$ trial. Blood samples were collected prior to administration of the product(s) and at 0.25 , $0.5,0.75,1,1.5,2,2.5,3,4,6,8$ and $12 \mathrm{~h}$ after dosing. Blood samples were centrifuged for separation of plasma and stored at or below $-20^{\circ} \mathrm{C}$ prior to analysis.

\section{HPLC Assay}

Plasma samples of $500 \mu \mathrm{l}$ were prepared for analysis by solid phase extraction, using Oasis HLB 1 cc cartridges (30 mg) supplied by Waters. The column was washed with $500 \mathrm{ml}$ 
water and then eluted with $500 \mu \mathrm{l}$ acetonitrile. The extract was centrifuged at $14000 \mathrm{rpm}$ for $10 \mathrm{~min}$ at $-5^{\circ} \mathrm{C}$ and the concentration of acyclovir was determined by LC-MS/MS using a sample injection volume of $10 \mu \mathrm{l}$. The bioanalytical method was modified from previously reported methods $(16,19,20)$. Validation data are included as supplementary material. The HPLC consisted of a Prontosil C18; 100*2, $00 \mathrm{~mm} ; 5 \mu \mathrm{m}$ column, using an Agilent 1100 LC binary pump. A gradient elution was used with mobile phase $\mathrm{A}$ and $\mathrm{B}$ where A consisted of $15 \mathrm{mM}$ ammonium acetate $+0.1375 \%$ formic acid at $\mathrm{pH} 3.5$ and $\mathrm{B}$ was acetonitrile $+0.1375 \%$ formic acid. Details of the gradient:

\begin{tabular}{lllll}
\hline Step & Total Time $(\mathrm{min})$ & Flow Rate $(\mu \mathrm{l} / \mathrm{min})$ & $\mathrm{A}(\%)$ & $\mathrm{B}(\%)$ \\
0 & 0.00 & 300 & 97.0 & 3.0 \\
1 & 0.50 & 300 & 97.0 & 3.0 \\
2 & 0.60 & 300 & 5.0 & 95.0 \\
3 & 1.20 & 300 & 5.0 & 95.0 \\
4 & 2.00 & 300 & 97.0 & 3.0 \\
5 & 5.50 & 300 & 97.0 & 3.0 \\
\hline
\end{tabular}

Detection took place by a triple quadrupole LC-MS/MS mass spectrometer, API 3000 manufactured by AB Sciex Instruments, using multiple reactions monitoring with transitions Q1/Q3: 255,992 $\rightarrow 151,873$. Source temperature was $500^{\circ} \mathrm{C}$, overall run time was $5.5 \mathrm{~min}$. The method was linear in a range of 10 to $800 \mathrm{ng} / \mathrm{ml}$, with a detection limit of $1 \mathrm{ng} / \mathrm{ml}$. QC samples were analyzed with the plasma samples to monitor method accuracy and precision.

\section{Pharmacokinetic and Statistical Analysis}

The data were analyzed using Microsoft Excel 2010 and IBM SPSS Statistics version 19. Maximum plasma concentration, $\mathrm{C}_{\max }$, and the time point at which this was measured, $\mathrm{T}_{\max }$, were manually selected from the data. The areas under the curve, $\mathrm{AUC}_{(0-\mathrm{t})}$ and $\mathrm{AUC}_{(0-\infty)}$, were estimated using the linear trapezoidal method as available in PKSolver2.0 with automatic calculation of the terminal elimination slope using the regression with the largest adjusted $\mathrm{R}^{2}$ based on at least three of the last time points (21).

The complete dataset was analyzed for sequence or period effects on $\mathrm{C}_{\max }$ and $\mathrm{AUC}$ using a general linear model with period, treatment, sequence and subject within sequence as fixed effects. The difference between related parameters was considered statistically significant if $p \leq 0.05$.

Parametric 90\% confidence intervals were calculated based on the univariate ANOVA of the mean ratio of test versus reference using log-transformed $\mathrm{C}_{\max }$ and $\mathrm{AUG}$ data. An increase of the bioavailability of more than $30 \%$ was predefined as clinically significant. In addition, the products were evaluated based on the European Guideline on bioequivalence. Test and reference products were considered bioequivalent if the ln-transformed ratios of $\mathrm{C}_{\max }$ and $\mathrm{AUC}$ and their confidence intervals were within the equivalence range of $80-125 \%$ (22).

$\mathrm{T}_{\max }$ was analysed using the nonparametric Wilcoxon signed rank test, where $p \leq 0.05$ was considered statistically significant.

\section{Tolerability}

Tolerability was assessed by monitoring electrocardiogram and blood parameters before and after the study and by subject interviews during the study.

\section{RESULTS \\ Tolerability}

The formulations were well tolerated. No adverse events were reported.

\section{Study Design and Data Evaluation}

Table I shows the $p$-values of the potential treatment, period, sequence and subject within sequence effects obtained for the parameters $\mathrm{AUC}_{(0-12)}, \mathrm{AUC}_{(0-\infty)}$ and $\mathrm{C}_{\max }$, which were all above 0.05 . These data confirmed absence of period or sequence effects and justified pooling of the data of each of the two doses of chitosan obtained at the two different time points. The pooled data were compared to the data obtained with reference product Zovirax.

Figures 1, 2, and 3 show the mean plasma curves obtained and an overview of individual data. The individual plasma profiles are accessible as supplementary material. The individual AUC data were considered sufficiently reliable as $\mathrm{AUC}_{0_{0}}$ 12) was $>80 \% \mathrm{AUC}_{(0-\infty)}$ in all cases, except for one in a test situation with $400 \mathrm{mg}$ chitosan $\mathrm{HCl}$ where $\mathrm{AUC}_{(0-12)}$ was $67 \%$ of $\mathrm{AUC}_{(0-\infty)}$. All data were used in the analysis..

Table I P-Values for Effects on $\mathrm{AUC}_{(0-12)}, \mathrm{AUC}_{(0-\infty)}$ and $\mathrm{C}_{\max }$

\begin{tabular}{llll}
\hline \multirow{2}{*}{ Source } & \multicolumn{2}{l}{$p$-values $(\alpha=0.1)$} & \\
\cline { 2 - 4 } & $\operatorname{A\cup C}_{(0-12)}$ & $\operatorname{A\cup C}_{(0-\infty)}$ & $C_{\text {max }}$ \\
\hline Treatment & 0.883 & 0.713 & 0.913 \\
Period & 0.900 & 0.975 & 0.544 \\
Sequence & 0.285 & 0.208 & 0.218 \\
Subject within sequence & 0.686 & 0.487 & 0.594 \\
\hline
\end{tabular}




\section{Comparative Evaluation of Pharmacokinetic Data}

Table II shows the pharmacokinetic data for each of the treatments; including comparative data of previously reported pharmacokinetic data of $200 \mathrm{mg}$ doses of acyclovir. $\mathrm{C}_{\max }$, $\mathrm{T}_{\max }$ and AUC values of the reference product were of the same magnitude as the data reported previously, both with regard to the mean values as well as to standard deviations $(13,18)$. The mean values obtained for the $\mathrm{G}_{\max }$ and $\mathrm{AUC}$ in presence of chitosan are lower than reference values reported in literature, whereas the standard deviations for $\mathrm{C}_{\max }$ and $\mathrm{T}_{\max }$ in presence of chitosan are higher. The elimination half-lives are also similar to those reported by others.

Tables III and IV list the point estimate and the $90 \%$ confidence interval for $\mathrm{AUC}$ and $\mathrm{C}_{\max }$ for each of the two doses of test product versus the reference product. Comparison of reference acyclovir with the two situations of concomitant chitosan intake show that both the arithmetic mean of the original data and the geometric mean of the ratios (GMR) of the AUC and $\mathrm{C}_{\max }$ decreased in presence of chitosan. The individual data show how in 9 out of 12 cases the $\mathrm{C}_{\max }$ and $A U \mathrm{C}$ values of reference Zovirax are indeed higher than those of the combinations with chitosan.

The confidence intervals of the geometric mean ratios for $\mathrm{AUC}_{(0-12)}$ and $\mathrm{AUC}_{(0-\infty)}$ concerning $400 \mathrm{mg}$ chitosan $\mathrm{HCl}$, included 1.00 and could thus not confirm a significant effect. However, those for the $1000 \mathrm{mg}$ dose of chitosan did not

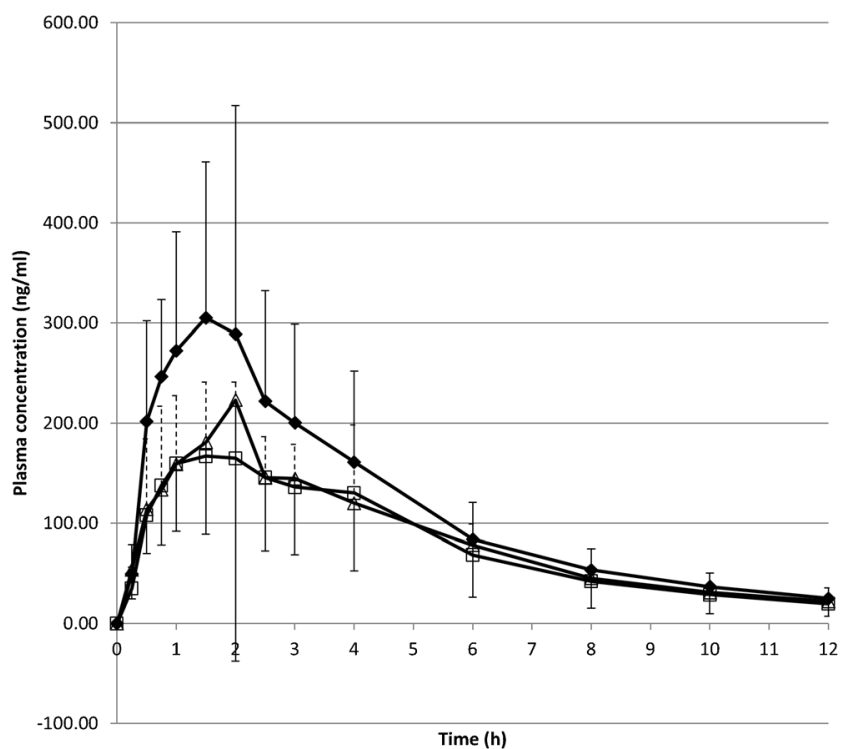

$\rightarrow$ Zovirax $\square$ Zovirax $+400 \mathrm{mg}$ chitosanHCl $\triangle$ Zovirax $+1000 \mathrm{mg}$ chitosanHCl

Fig. I Mean acyclovir plasma profiles. For clarity of the figure, only one-way error bars representing the standard deviation are shown. Positive bars are shown for the Zovirax reference and for Zovirax with the $400 \mathrm{mg}$ chitosan dose (dashed line). Negative bars are shown for Zovirax with the $1000 \mathrm{mg}$ chitosan dose. The actual standard deviations were equal in both positive and negative direction. include 1.00 , pointing to a significant negative effect. The lower boundary of the $90 \%$ confidence intervals for $\mathrm{AUC}_{(0-}$ 12) and $\mathrm{AUC}_{(0-\infty)}, 0.50$ resp. 0.51 , show how this decrease could be up to about 2-fold compared to the reference value.

For $\mathrm{C}_{\max }$, neither $90 \%$ confidence interval includes 1.00 , thereby demonstrating a significant decrease in $\mathrm{C}_{\max }$ of acyclovir in presence of both doses of chitosan. This effect is at least $10 \%$ for the $400 \mathrm{mg}$ dose and $12 \%$ for the $1000 \mathrm{mg}$ dose. The confidence intervals for the 400 and $1000 \mathrm{mg}$ doses almost completely overlap: the median effect is a decrease by $41-42 \%$ to values of $58-59 \%$ of the reference value (see GMR values). The decrease could be at maximum $61-62 \%$, i.e. to values as low as $38-39 \%$ of the reference $\mathrm{C}_{\max }$, considering the lower boundaries of the confidence intervals.

The $\mathrm{T}_{\max }$ obtained with $400 \mathrm{mg}$ chitosan $\mathrm{HCl}$ is not significantly different from the $\mathrm{T}_{\max }$ of the reference Zovirax. However, $\mathrm{T}_{\max }$ increased significantly in presence of $1000 \mathrm{mg}$ of chitosan from 1 to $2 \mathrm{~h}(p=0.029)$.

\section{DISCUSSION}

The results obtained with the acyclovir reference product were in line with those published by others, both regarding the magnitude of the mean values as well as the standard deviations (see Table II).

The effects of chitosan on the bioavailability of acyclovir from Zovirax were evaluated in the context of a pretreatment with Zovirax, as administered to all volunteers on the first trial day. In view of the half-life of acyclovir of about $3 \mathrm{~h}$, a carryover effect of pretreatment with Zovirax is not expected to play a role and the order of administration of the test and reference products is not expected to affect the results (23).

Locally administered chitosan increased acyclovir's permeability across Caco-2 membranes and facilitated the absorption of acyclovir in rats (15-17). The clinical trial protocol was based on an expected increase of $\mathrm{C}_{\max }$ and $\mathrm{AUC}$ and defined that an increase by $30 \%$ would be considered as relevant. However, chitosan $\mathrm{HCl}$ did not act as absorption enhancer of acyclovir in the human study presented here. None of the confidence intervals includes a value of 1.3 or more, so an increase by $30 \%$ is highly unlikely.

Masuda et al. postulated a cut-off value of $10 \mathrm{kDa}$ as minimal chain length of the chitosan polysaccharide to facilitate acyclovir's absorption. Opanasopit et al. showed an increasing negative effect on the transepithelial electric resistance of Caco-2 monolayers with increasing MW in the range of 20$460 \mathrm{kDa}(24)$. The applied chitosan had a MW of 30-400 kDa which is well within these ranges. Masuda et al. also found a dose dependent effect and the authors explained its transience by dilution of the concentration at the site of action and by neutralization of the acidified perfusate by the intestinal fluids. 
Fig. 2 Individual data for $A \cup C_{(0-12)}$

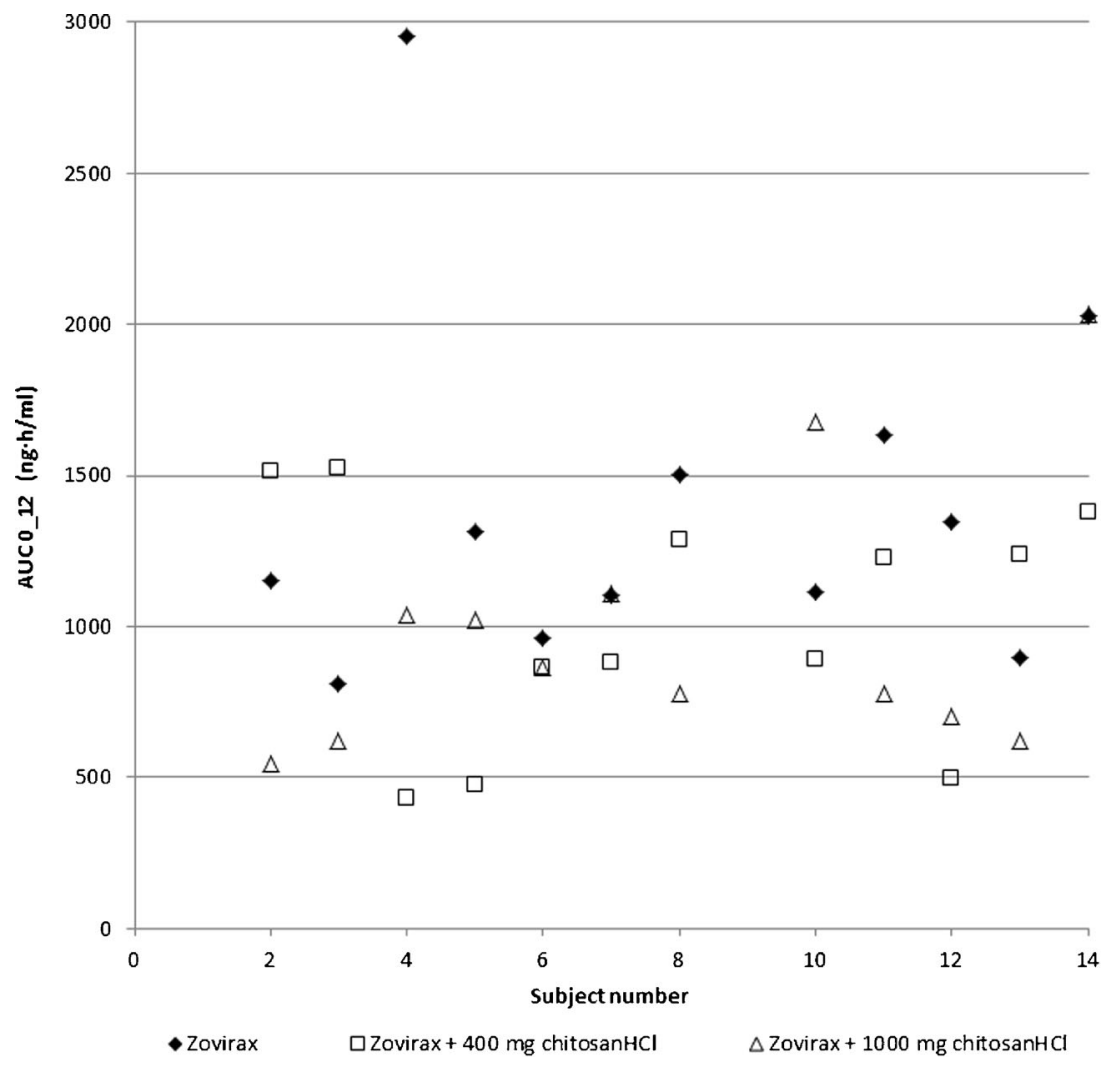

An enhancing effect due to changes in viscosity or cationic charges only was not found likely. Here, chitosan $\mathrm{HCl}$ and

acyclovir were administered orally and their concentrations were diluted by the luminal fluids while progressing through

Fig. 3 Individual data for $C_{\text {max }}$

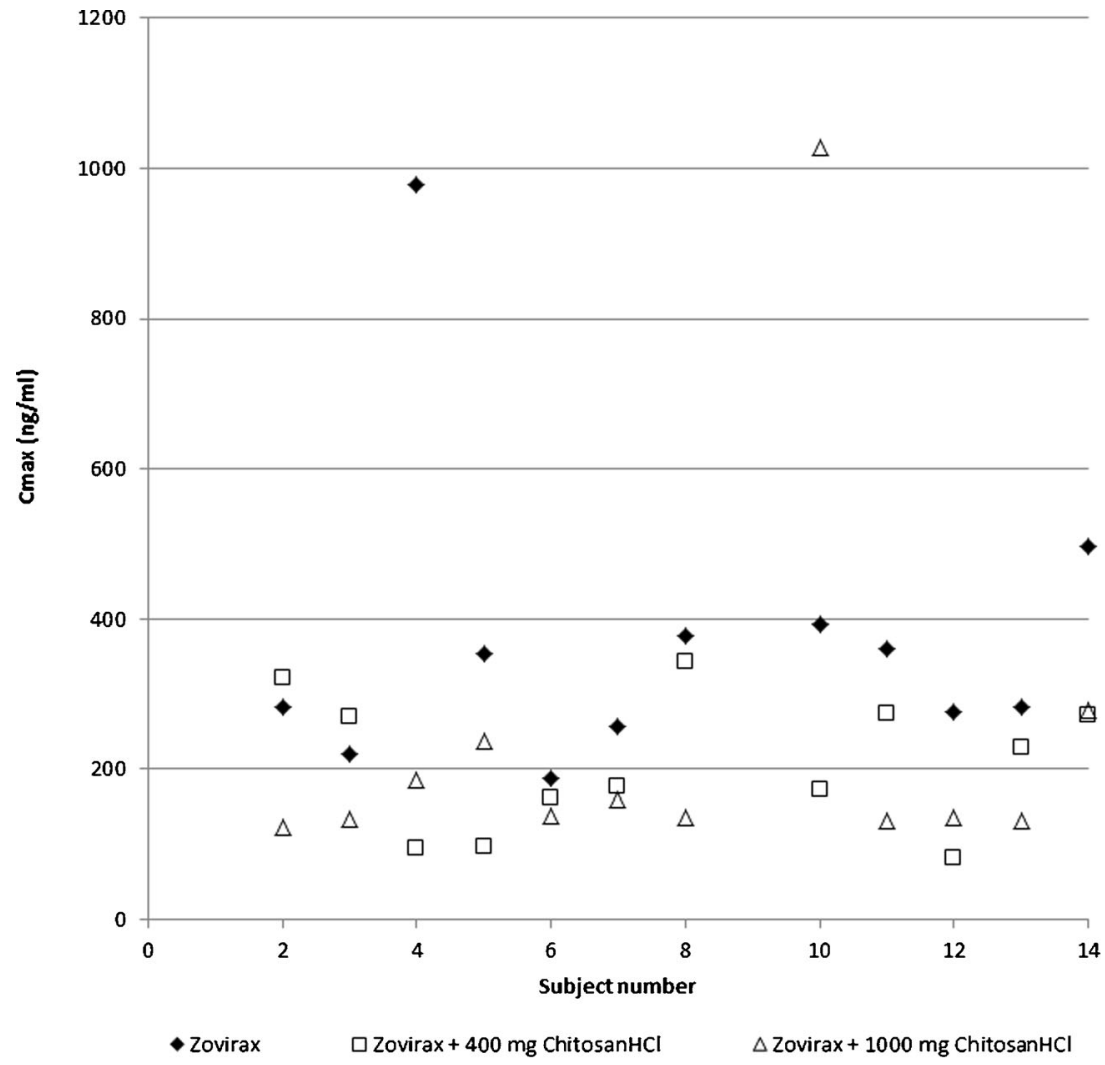


Table II Pharmacokinetic Data (Mean Values \pm sd) of a 200 mg Dose of Acyclovir, Including Comparison with Literature

\begin{tabular}{|c|c|c|c|c|c|c|}
\hline Parameter & Zovirax & $\begin{array}{l}\text { Zovirax }+400 \text { mg } \\
\text { Chitosan HCl }\end{array}$ & $\begin{array}{l}\text { Zovirax + } 1000 \text { mg } \\
\text { Chitosan HCl }\end{array}$ & Reference (I) & Reference (2) & Reference (3) \\
\hline $\begin{array}{l}\mathrm{C}_{\max } \\
(\mathrm{mg} / \mathrm{ml})\end{array}$ & $0.373 \pm 0.209$ & $0.208 \pm 0.090$ & $0.235 \pm 0.255$ & $0.3 \pm 0.1(c, s)$ & $\begin{array}{l}0.454 \pm 0.165(t) \\
0.525 \pm 0.205(r)\end{array}$ & $\begin{array}{l}0.677 \pm 0.209(t) \\
0.707 \pm 0.239(r)\end{array}$ \\
\hline $\begin{array}{l}T_{\max } \\
\text { (h) }\end{array}$ & $1.2 \pm 0.4$ & $1.5 \pm 0.9$ & $1.8 \pm 0.9$ & $\begin{array}{l}1.5 \pm 0.6(\mathrm{c}) \\
1.2 \pm 0.3(\mathrm{~s})\end{array}$ & $\begin{array}{l}1.6 \pm 0.7(t) \\
1.6 \pm 0.7(r)\end{array}$ & $\begin{array}{l}1.5 \pm 0.5(t) \\
1.5 \pm 0.4(r)\end{array}$ \\
\hline $\begin{array}{l}\text { AUC }_{0 \text {-inf }} \\
(\mathrm{mg} \cdot \mathrm{h} / \mathrm{ml})\end{array}$ & $1.528 \pm 0.627$ & $1.132 \pm 0.418$ & $1.074 \pm 0.509$ & $\begin{array}{l}1.5 \pm 0.5(\mathrm{c}) \\
1.6 \pm 0.5(\mathrm{~s}) \\
\left(A \cup C_{0-24}\right)\end{array}$ & $\begin{array}{l}2.375 \pm 0.739(t) \\
2.632 \pm 0.927(r)\end{array}$ & $\begin{array}{l}3.422 \pm 1.309(\mathrm{t}) \\
3.518 \pm 1.211(\mathrm{r})\end{array}$ \\
\hline $\begin{array}{l}t_{1 / 2} \\
(h)\end{array}$ & $3.4 \pm 1.1$ & $3.5 \pm 1.0$ & $3.2 \pm 0.6$ & $\begin{array}{l}2.9 \pm 0.8(c) \\
2.9 \pm 0.7(s)\end{array}$ & $\begin{array}{l}3.15 \pm 0.60(t) \\
3.04 \pm 0.58(r)\end{array}$ & $\begin{array}{l}4.49 \pm 2.37(t) \\
3.93 \pm 2.65(r)\end{array}$ \\
\hline
\end{tabular}

I. de Miranda P, Blum MR. Pharmacokinetics of acyclovir after intravenous and oral administration. J Antimicrob Chemother. 1983; I2 Suppl B:29-37.

2. Vergin H, Kikuta C, Mascher H, Metz R. Pharmacokinetics and bioavailability of different formulations of aciclovir. Arzneimittelforschung. 1995;45(4):508-15. 3. Rojanasthien N, Teekachunhatean S, Kumsorn B, Chaichana N, Hay YK. Bioequivalence study of generic acyclovir compared with the brand name acyclovir. J Med Assoc Thail. 2002;85( I0): I I 21-9.

$t$ test, $r$ reference tablet, $c$ capsule, $s$ solution

the gastrointestinal tract, probably resulting in insufficiently high concentrations at acyclovir's absorption site. Moreover, the actually dissolved and protonated fraction of chitosan may have been too low at gastrointestinal $\mathrm{pH}$, thereby limiting a charge-based interaction with the epithelial membrane (25).

Chitosan is metabolized in the colon, a property that has been used to produce colon targeted formulations (26). Although evidence suggests that chitosan metabolism is likely to mainly take place in the colon, the concentration at acyclovir's absorption site may also have been decreased by enzymatic degradation in stomach (pepsin) and/or duodenum/ ileum (pancreatic enzymes) (27-32). In addition, the presence of mucus may represent an unfavorable microenvironment and have hampered the access of chitosan to the mucosa to exert its permeability enhancing effect $(33,34)$.

If the data were to be evaluated as a bioequivalence study, a confidence interval contained within 0.8 to 1.25 would be considered as bioequivalent and confirm absence of clinically relevant difference. Considering the lower values of each of the $90 \%$ confidence intervals, which are all well below 0.8 , the data do not confirm bioequivalence of the combination of Zovirax with chitosan to Zovirax only. In fact, the data unexpectedly show a reduced bioavailability of acyclovir in presence of chitosan $\mathrm{HCl}$. $\mathrm{C}_{\max }$ was significantly reduced by both

Table III Comparative Evaluation of $200 \mathrm{mg}$ Zovirax p.o. Without (Reference) and with (Test) Concomitant $400 \mathrm{mg}$ Chitosan $\mathrm{HCl}$

\begin{tabular}{llll}
\hline $\begin{array}{l}\text { Pharmacokinetic } \\
\text { parameter }\end{array}$ & $\begin{array}{l}\text { Geometric mean ratio } \\
\text { test/reference }\end{array}$ & $\begin{array}{l}90 \% \text { Confidence } \\
\text { intervals }\end{array}$ & $\begin{array}{l}\text { CV } \\
(\%)\end{array}$ \\
\hline A C $_{(0-12)}$ & 0.72 & $0.51-1.13$ & 46 \\
U C $_{(0-\infty)}$ & 0.73 & $0.54-1.00$ & 42 \\
$C_{\max }$ & 0.59 & $0.39-0.90$ & 57 \\
\hline
\end{tabular}

chitosan doses, and AUC and $\mathrm{T}_{\max }$ only by the $1000 \mathrm{mg}$ chitosan dose. Dose dependency could not be demonstrated as point estimates for $\mathrm{AUC}$ and $\mathrm{C}_{\max }$ were close and the confidence intervals for both doses of chitosan almost completely overlap. Confirmatory studies may clarify the actual significance and magnitude of the observed negative effects on the means.

Acyclovir is known for its variable absorption. De Miranda and Blum described how a $200 \mathrm{mg}$ acyclovir outperformed a $200 \mathrm{mg}$ acyclovir solution in as many subjects as vice versa thereby demonstrating how the variability in absorption is a substance related characteristic and not product related (21). Figures 2 and 3 also show variable individual effects in absence and presence of chitosan: contrary to the results of the means, three volunteers actually showed an increase of the bioavailability for one of the chitosan doses. The standard deviations calculated for $\mathrm{AUC}$ and $\mathrm{C}_{\max }$ remain comparable to literature data in presence of chitosan (see Table II). However, the standard deviation for $\mathrm{T}_{\max }$ is higher than literature values for the reference product. Several mechanisms may have influenced the bioavailability of acyclovir. Considering the effects on the variability of $\mathrm{T}_{\max }$, the significant effects on $\mathrm{C}_{\max }$ and AUC, and other hand, the similarity of the terminal half-lives

Table IV Comparative Evaluation of $200 \mathrm{mg}$ Zovirax p.o. Without (Reference) and with (Test) Concomitant $1000 \mathrm{mg}$ Chitosan $\mathrm{HCl}$

\begin{tabular}{llll}
\hline $\begin{array}{l}\text { Pharmacokinetic } \\
\text { parameter }\end{array}$ & $\begin{array}{l}\text { Geometric mean ratio } \\
\text { test/reference }\end{array}$ & $\begin{array}{l}90 \% \text { Confidence } \\
\text { intervals }\end{array}$ & $\begin{array}{l}\mathrm{CV} \\
(\%)\end{array}$ \\
\hline $\mathrm{AUC}_{(0-12)}$ & 0.70 & $0.50-0.99$ & 46 \\
$\mathrm{AUC}_{(0-\infty)}$ & 0.69 & $0.51-0.94$ & 42 \\
$\mathrm{Cmax}_{\max }$ & 0.58 & $0.38-0.88$ & 57 \\
\hline
\end{tabular}


with reference values, chitosan's effect seems to mainly take place in the absorption phase.

Literature evidence does not point to interaction between chitosan $\mathrm{HCl}$ and acyclovir leading to degradation of acyclovir, either in a formulation or in the gut lumen. An effect of chitosan $\mathrm{HCl}$ on the dissolution (rate) of acyclovir at the time of administration is conceivable. The tablets were dispersed in $100 \mathrm{~mL}$ water or $100 \mathrm{~mL}$ chitosan solution and the glass was rinsed with another $150 \mathrm{~mL}$ of water. In view of acyclovir's solubility of $\geq 2.3 \mathrm{mg} / \mathrm{mL}$ in $\mathrm{pH}$ range $1.2-7.4$ at $37^{\circ} \mathrm{C}$ and the expected final concentration $2 \mathrm{mg} / \mathrm{mL}$ in the first $100 \mathrm{~mL}$ water at room temperature, not all acyclovir may have been dissolved (35,36). However, after addition of $150 \mathrm{ml}$ water and assuming the presence of additional volume of aqueous fluids and a temperature of $37^{\circ} \mathrm{C}$ in the stomach, acyclovir was expected to dissolve sufficiently well. Experiments [data not shown] indeed confirmed the visual compatibility of $1 \mathrm{~g}$ chitosan $\mathrm{HCl}$ with $200 \mathrm{mg}$ pure acyclovir after $1 \mathrm{~min}$ of stirring in $250 \mathrm{~mL}$ water at room temperature, resulting in a clear solution. In addition, any residues of undissolved acyclovir were expected to be similar for reference and test situations.

Acyclovir's solubility is at the borderline of BCS class III and IV. Increasing its solubility in the lumen may improve its bioavailability, as demonstrated by the effects of a selfmicroemulsifying drug delivery system (37). Vice versa, its solubility may become limiting if it is chemically or physiologically reduced. Allam et al. showed how chitosan-acyclovir co-crystals prolonged the release of acyclovir, however, the crystal formation was not observed when acyclovir and chitosan were dissolved in $250 \mathrm{~mL}$ water [data not shown] (38). Nadai et al. showed how chitosan $\left(25 \mathrm{mg} / \mathrm{kg}\right.$ ) prolonged $\mathrm{T}_{\max }$ of orally administered suspensions of indomethacin and griseofulvin in rats, and reduced $\mathrm{C}_{\max }$ and $\mathrm{AUC}$. Association of the anionic indomethacin to the tertiary amino groups of chitosan did not play a role according to those authors (39). The molecular structures of chitosan ( $\mathrm{pKa} \sim 6-6.5$ ) and acyclovir (pKa's 2.3 and 9.3) do not seem to favor charge based complex formation or adsorption either (40).

Effects on $\mathrm{T}_{\max }$ and $\mathrm{C}_{\max }$ may be related to the gastric emptying time; whereas an effect on intestinal transit time may be relevant for the absorption of the BCS class III compound acyclovir. It was previously found unlikely that chitosan caused alterations in the gastric emptying rate, as the delayed $\mathrm{T}_{\max }$ was not observed for other compounds (39). However, in the current case, the difference in stomach content after ingestion of the chitosan dispersion (increased osmotic value, lower $\mathrm{pH}$, perceived nutrient density) compared the reference dispersion may have influenced the gastric emptying rate which may explain the variable effect on $\mathrm{C}_{\max }$ and $\mathrm{T}_{\max }$.

Nadai et al. postulated an indirect effect as a cause for the prolonged $\mathrm{T}_{\max }$ : binding of bile acids to chitosan resulting in inhibition of the solubilisation of the drug substances (39). Heinen et al. indeed described how presence and reduction of bile salts affected the absorption of BCS class III drug trospium chloride (41). In fact, the absorption of acyclovir increased in presence of conjugated trihydroxy bile salts and bile saltacylcarnitine mixed micelles $(42,43)$. The $1000 \mathrm{mg}$ chitosan $\mathrm{HCl}$ used in the clinical study presented here corresponds to about $14 \mathrm{mg} / \mathrm{kg}$ for a human being of $70 \mathrm{~kg}$ and is thus of the same order of magnitude as the dose used by Nadai et al. Although amphoteric acyclovir is in neutral state at physiological $\mathrm{pH}$ and is not known for having a significant food effect, chitosan may have interacted with luminal bile components indirectly resulting in a reduced bioavailability of acyclovir $(14,36)$.

Finally, chitosan may act at the site of absorption. Chitosan's mucoadhesive properties have been studied in potentially absorption enhancing formulations of acyclovir (44-46). Although no literature evidence is known to the authors, theoretically, chitosan may have physically or biochemically delayed or prevented access of acyclovir to its paracellular permeation route by binding to mucus at the absorption site and/or changing the microclimate e.g. by formation of a protective viscous layer. Derivatives of chitosan, quercetin and DM72 have been shown to inhibit the efflux of acyclovir via P-gp, with the aim of improving its bioavailability (47-49). An opposite effect, i.e. induction of (expression of P-gp by chitosan has not been described and seems an unlikely effect of a single dose of chitosan.

An effect of chitosan on the metabolism of drugs has not been described. As acyclovir is eliminated mainly in unchanged form, such interaction is not considered likely either (14).

As chitosan is currently not in use as an excipient in approved drug products, the clinical impact of the results seems limited. However, the observed variability and complex potential interactions may complicate the use of chitosan $\mathrm{HCl}$ in oral pharmaceutical formulations. In addition, chitosan is advertised as food supplement in high doses, up to $6 \mathrm{~g}$ a day; interactions with concomitant pharmacotherapy seem possible (50).

\section{CONCLUSION}

The results of this study in human volunteers did not confirm the data obtained in in vitro experiments and in rats studies that suggested that chitosan would improve the bioavailability of acyclovir. Chitosan increased the variability of the absorption of acyclovir and significantly reduced its absorption. Mechanistic studies are needed to investigate the cause for the discrepancy in these results. A luminal interaction of chitosan 
with acyclovir, bile salts or the epithelial membrane may be responsible for the negative effects on acyclovir's absorption.

\section{ACKNOWLEDGMENTS AND DISCLOSURES}

The authors wish to thank Dr. Dirk Barends for initializing this project; unfortunately, Dirk passed away before the results became available. This study was performed as a part of the RIVM Biothree project, for which FIP kindly provided seed funding. The clinical study was sponsored by the Product Quality Research Institute. Alexander Soliman is acknowledged for his contribution in organization of the clinical trial. The authors wish to thank Maria Teresa Sendra Todo for the development and performance of the bioanalytics.

This work is contributing to the Innovative Medicines Initiative Joint Undertaking (http://www.imi.europa.eu) under Grant Agreement No. 115369 as in kind contribution. M.K. is employed at the MEB, but the views presented here do not necessarily reflect the opinion of the Board.

Open Access This article is distributed under the terms of the Creative Commons Attribution License which permits any use, distribution, and reproduction in any medium, provided the original author(s) and the source are credited.

\section{REFERENCES}

1. Aungst BJ. Absorption enhancers: applications and advances. Aaps J. 2012;14(1):10-8.

2. Takatsuka S, Morita T, Horikiri Y, Yamahara H, Saji H. Influence of various combinations of mucolytic agent and non-ionic surfactant on intestinal absorption of poorly absorbed hydrophilic compounds. Int J Pharm. 2008;349(1-2):94-100.

3. Goole J, Lindley DJ, Roth W, Carl SM, Amighi K, Kauffmann JM, et al. The effects of excipients on transporter mediated absorption. Int J Pharm. 2010;393(1-2):17-31.

4. Artursson P, Lindmark T, Davis SS, Illum L. Effect of chitosan on the permeability of monolayers of intestinal epithelial cells (Caco-2). Pharm Res. 1994;11(9):1358-61.

5. Schipper NG, Varum KM, Artursson P. Chitosans as absorption enhancers for poorly absorbable drugs. 1: influence of molecular weight and degree of acetylation on drug transport across human intestinal epithelial (Caco-2) cells. Pharm Res. 1996;13(11):1686-92.

6. Cano-Gebrian MJ, Zornoza T, Granero L, Polache A. Intestinal absorption enhancement via the paracellular route by fatty acids, chitosans and others: a target for drug delivery. Curr Drug Deliv. 2005;2(1):9-22.

7. Deli MA. Potential use of tight junction modulators to reversibly open membranous barriers and improve drug delivery. Biochim Biophys Acta. 2009;1788(4):892-910.

8. Schipper NG, Olsson S, Hoogstraate JA, de Boer AG, Varum KM, Artursson P. Chitosans as absorption enhancers for poorly absorbable drugs 2: mechanism of absorption enhancement. Pharm Res. 1997;14(7):923-9.

9. Gonzalez-Mariscal L, Nava P, Hernandez S. Critical role of tight junctions in drug delivery across epithelial and endothelial cell layers. J Membr Biol. 2005;207(2):55-68.
10. Illum L. Chitosan and its use as a pharmaceutical excipient. Pharm Res. 1998;15(9):1326-31.

11. Meadows KC, Dressman JB. Mechanism of acyclovir uptake in rat jejunum. Pharm Res. 1990;7(3):299-303.

12. Tanna S, Wood C, Lawrence MJ. Competition studies to elucidate the mechanisms of acyclovir uptake in the small intestine. J Pharm Pharmacol. 1992;44(Suppl1):1047.

13. de Miranda P, Blum MR. Pharmacokinetics of acyclovir after intravenous and oral administration. J Antimicrob Chemother. 1983;12(Suppl B):29-37.

14. The electronic Medicines Compendium (eMC) [Internet]. Datapharm communications limited. 2010 [cited 16 September 2010]. Available from: http://www.medicines.org.uk/emc/ medicine / 9273 / S P C / Z ovirax\% $20200 \mathrm{mg} \%$ 20Tablets\#tableOfContents.

15. Shah P, Jogani V, Mishra P, Mishra AK, Bagchi T, Misra A. In vitro assessment of acyclovir permeation across cell monolayers in the presence of absorption enhancers. Drug Dev Ind Pharm. 2008;34(3):279-88.

16. Merzlikine A, Rotter C, Rago B, Poe J, Christoffersen C, Thomas $\mathrm{VH}$, et al. Effect of chitosan glutamate, carbomer 974P, and EDTA on the in vitro Caco-2 permeability and oral pharmacokinetic profile of acyclovir in rats. Drug Dev Ind Pharm. 2009;35(9):1082-91.

17. Masuda A, Goto Y, Kurosaki Y, Aiba T. In vivo application of chitosan to facilitate intestinal acyclovir absorption in rats. J Pharm Sci. 2012;101(7):2449-56.

18. Vergin H, Kikuta C, Mascher H, Metz R. Pharmacokinetics and bioavailability of different formulations of aciclovir. Arzneimittelforschung. 1995;45(4):508-15.

19. Tian Y, Lin H, Zhang XY, Zhang ZJ, Mao GG. Rapid quantification of the metabolite of valacyclovir hydrochloride in human plasma by liquid chromatography-tandem mass spectrometry. Acad J Xi'an Jiaotong Univ. 2010;22(2):83-90.

20. Kanneti R, Rajesh R, Aravinda Raj JR, Bhatt PA. An LC-MS-MS method for the simultaneous quantitation of acyclovir and valacyclovir in human plasma. Chromatographia. 2009;70(3-4): 407-14.

21. Zhang Y, Huo M, Zhou J, Xie S. PKSolver: an add-in program for pharmacokinetic and pharmacodynamic data analysis in Microsoft Excel. Comput Methods Prog Biomed. 2010;99(3):306-14.

22. EMA. Guideline on the investigation of bioequivalence. European Medicines Agency; 2010.

23. Sweetman SCe. Martindale: the complete drug reference [online]. London: The Pharmaceutical Press; 2010. Available from: (http:// www.medicinescomplete.com/). Last accessed: 6 June 2014.

24. Opanasopit P, Aumklad P, Kowapradit J, Ngawhiranpat T, Apirakaramwong A, Rojanarata $\mathrm{T}$, et al. Effect of salt forms and molecular weight of chitosans on in vitro permeability enhancement in intestinal epithelial cells (Caco-2). Pharm Dev Technol. 2007;12(5):447-55.

25. Kotze AF, Thanou MM, Luebetaen HL, de Boer AG, Verhoef JC, Junginger HE. Enhancement of paracellular drug transport with highly quaternized N-trimethyl chitosan chloride in neutral environments: in vitro evaluation in intestinal epithelial cells (Caco-2). J Pharm Sci. 1999;88(2):253-7.

26. Bernkop-Schnürch A, Dünnhaupt S. Chitosan-based drug delivery systems. Eur J Pharm Biopharm. 2012;81(3):463-9.

27. Kean T, Thanou M. Biodegradation, biodistribution and toxicity of chitosan. Adv Drug Deliv Rev. 2010;62(1):3-11.

28. Baldrick P. The safety of chitosan as a pharmaceutical excipient. Regul Toxicol Pharmacol. 2009.

29. Nishimura Y, Kim HS, Ikota N, Arima H, Bom HS, Kim YH, et al. Radioprotective effect of chitosan in sub-lethally X-ray irradiated mice. J Radiat Res. 2003;44(1):53-8. 
30. Hirano S, Itakura C, Seino H, Akiyama Y, Nonaka I, Kanbara N, et al. Chitosan as an ingredient for domestic animal feeds. J Agric Food Chem. 1990;38(5):1214-7.

31. Okamoto Y, Nose M, Miyatake K, Sekine J, Oura R, Shigemasa Y, et al. Physical changes of chitin and chitosan in canine gastrointestinal tract. Carbohydr Polym. 2001;44(3):211-5.

32. McConnell EL, Murdan S, Basit AW. An investigation into the digestion of chitosan (noncrosslinked and crosslinked) by human colonic bacteria. J Pharm Sci. 2008;97(9):3820-9.

33. Hagesaether E. Permeation modulating properties of natural polymers-effect of molecular weight and mucus. Int J Pharm. $2011 ; 409(1-2): 150-5$.

34. Schipper NG, Varum KM, Stenberg P, Ocklind G, Lennernas H, Artursson P. Chitosans as absorption enhancers of poorly absorbable drugs. 3: influence of mucus on absorption enhancement. Eur J Pharm Sci. 1999;8(4):335-43.

35. Arnal J, Gonzalez-Alvarez I, Bermejo M, Amidon GL, Junginger HE, Kopp S, et al. Biowaiver monographs for immediate release solid oral dosage forms: aciclovir. J Pharm Sci. 2008;97(12):5061-73.

36. The Merck Index (C) 2006, 2012 Merck Sharp \& Dohme Corp, a subsidiary of Merck \& Co, Inc, Whitehouse Station, NJ, USA All rights reserved MedicinesComplete (C) The Pharmaceutical Press 2014 [Internet]. Last accessed: 14 February 2014.

37. Patel D, Sawant KK. Oral bioavailability enhancement of acyclovir by self-microemulsifying drug delivery systems (SMEDDS). Drug Dev Ind Pharm. 2007;33(12):1318-26.

38. Allam AN, Naggar VF, El Gamal SS. Formulation and physicochemical characterization of chitosan/acyclovir co-crystals. Pharm Dev Technol. 2013;18(4):856-65.

39. Nadai M, Tajiri C, Yoshizumi H, Suzuki Y, Zhao YL, Kimura M, et al. Effect of chitosan on gastrointestinal absorption of waterinsoluble drugs following oral administration in rats. Biol Pharm Bull. 2006;29(9):1941-6.

40. Wang QZ, Ghen XG, Liu N, Wang SX, Liu CS, Meng XH, et al. Protonation constants of chitosan with different molecular weight and degree of deacetylation. Carbohydr Polym. 2006;65(2):194-201.

41. Heinen CA, Reuss S, Amidon GL, Langguth P. Ion pairing with bile salts modulates intestinal permeability and contributes to food-drug interaction of BCS CLASS III compound trospium chloride. Mol Pharm. 2013;10(11):3989-96.

42. Park GB, Shao Z, Mitra AK. Acyclovir permeation enhancement across intestinal and nasal mucosae by bile salt-acylcarnitine mixed micelles. Pharm Res. 1992;9(10):1262-7.

43. Shao Z, Mitra AK. Nasal membrane and intracellular protein and enzyme release by bile salts and bile salt-fatty acid mixed micelles: correlation with facilitated drug transport. Pharm Res. 1992;9(9): 1184-9.

44. Dhaliwal S, Jain S, Singh HP, Tiwary AK. Mucoadhesive microspheres for gastroretentive delivery of acyclovir: in vitro and in vivo evaluation. Aaps J. 2008;10(2):322-30.

45. Ruiz-Caro R, Gago-Guillan M, Otero-Espinar FJ, Veiga MD. Mucoadhesive tablets for controlled release of acyclovir. Chem Pharm Bull. 2012;60(10):1249-57.

46. Naderkhani E, Erber A, Skalko-Basnet N, Flaten GE. Improved permeability of acyclovir: optimization of mucoadhesive liposomes using the phospholipid vesicle-based permeation assay. J Pharm Sci. 2014;103(2):661-8.

47. Yang ZG, Meng H, Zhang X, Li XD, Lv WL, Zhang Q. Effect of quercetin on the acyclovir intestinal absorption. Beijing Da Xue Xue Bao. 2004;36(3):309-12.

48. Salama NN, Scott KR, Eddington ND. DM27, an enaminone, modifies the in vitro transport of antiviral therapeutic agents. Biopharm Drug Dispos. 2004;25(5):227-36.

49. Palmberger TF, Hombach J, Bernkop-Schnurch A. Thiolated chitosan: development and in vitro evaluation of an oral delivery system for acyclovir. Int J Pharm. 2008;348(1-2):54-60.

50. Jull AB, Ni Mhurchu C, Bennett DA, Dunshea-Mooij CA, Rodgers A. Chitosan for overweight or obesity. Cochrane Database Syst Rev. 2008(3):CD003892. 